\title{
Self-Care Modeling Videos for Spinal Cord Injuries: Design and Production of a Prototype
}

\author{
Vídeos Simuladores de Autocuidado em Lesão Medular: Conceção e Produção de um \\ Protótipo \\ Vídeos Simuladores de Autocuidado en Lesión Medular: Concepción y Producción de un \\ Prototipo
}

Catarina Isabel Reis Silva Garcia e Teles de Araújo*

\begin{abstract}
Background: The use of videos in the rehabilitation of spinal cord injury (SCI) patients allows providing additional information on self-care techniques/exercises.

Objectives: To identify the information needs of SCI patients, and produce and validate the contents of self-care training videos for SCI patients.

Methodology: Qualitative study on the design and validation of a video prototype. Following a preliminary study on the information needs of SCI patients using a group of SCI patients and another group of rehabilitation professionals, 10 videos focused on rehabilitation techniques were created. The contents of these videos were then validated by 7 experts.

Results: The most common suggestions from the interviewed experts were: positioning/movement of the SCI patient; use of alternative assistive devices; changes in shooting image, rhythm, duration or angle.

Conclusion: The videos were assessed as reasonable to very good. The experts referred that the videos offer educational benefits when compared to written materials, such as manuals or leaflets.
\end{abstract}

Keywords: instructional films and videos; rehabilitation; spinal cord injuries; self-care; motor skills

\section{Resumo}

Enquadramento: A utilização de vídeos em reabilitação de pessoas com lesão medular (LM) permite transmitir informação complementar sobre técnicas/exercícios de autocuidado.

Objetivos: Identificar necessidades de informação de pessoas com LM e produzir e validar os conteúdos do treino de autocuidado em pessoas com LM passíveis de transmitir em vídeo.

Metodologia: Estudo qualitativo, de conceção e validação de um protótipo em vídeo. Após um estudo preliminar sobre necessidades de informação de pessoas com LM, segundo um grupo de pessoas com LM e um grupo de profissionais de reabilitação, foi produzido um conjunto de 10 vídeos visando técnicas de reabilitação. Os vídeos produzidos foram depois sujeitos a validação de conteúdo por 7 peritos.

Resultados: As críticas mais frequentes nas entrevistas aos peritos foram: posição/movimento da pessoa com LM; alternativas em produtos de apoio; alterações da imagem, ritmo, duração ou ângulo de filmagem.

Conclusão: Foi atribuída uma avaliação dos vídeos entre razoável a muito bom. Os peritos admitiram que os vídeos oferecem vantagens didáticas face a materiais escritos como manuais ou folhetos.

Palavras-chave: filmes e vídeos educativos; reabilitação; traumatismos da medula espinal; autocuidado; destreza motora

* Ph.D., Enfermeira Especialista, Centro de Medicina de Reabilitação de Alcoitão, 2649-506, Alcabideche, Portugal [garciacatarina@hotmail.com]. Morada para correspondencia: Rua Conde Barão - Alcoitão, 2649-506, Alcabideche, Portugal.

\section{Resumen}

Marco contextual: La utilización de vídeos en la rehabilitación de personas con lesión medular (LM) permite transmitir información sobre técnicas/ejercicios como complemento para los programas de autocuidado.

Objetivos: Identificar las necesidades de información de las personas con LM, así como producir y validar los contenidos relativos al entrenamiento del autocuidado en personas con LM que puedan ser transmitidos en vídeo.

Metodología: Adoptamos una metodología cualitativa con el objetivo de crear y validar un prototipo en vídeo y en lengua portuguesa. Tras realizar un estudio preliminar sobre las necesidades de información de los pacientes con LM con un grupo de personas con LM y un grupo de profesionales de rehabilitación, se creó un conjunto de 10 vídeos que incluyen técnicas de rehabilitación. Posteriormente, el contenido de los vídeos producidos fue validado por 7 expertos en el área.

Resultados: Las críticas más frecuentes en las entrevistas a los expertos fueron: posición/movimiento de la persona con LM; alternativas en productos de apoyo; alteraciones de la imagen, ritmo, duración y ángulo de rodaje.

Conclusión: Los vídeos fueron valorados entre normal y muy bueno. Los expertos admitieron que los vídeos ofrecen ventajas didácticas frente a los materiales escritos, como manuales o folletos.

Palabras clave: películas y vídeos educativos; rehabilitación; traumatismos de la médula espinal; autocuidado; destreza motora

Received for publication: 26.10 .15

Accepted for publication: 26.01.16 


\section{Introduction}

People with mobility impairments have been encouraged to manage their own self-care. Within the family and at home, rehabilitation patients have increased responsibility and self-management of information on therapeutic regimens, medication forms, specific clinical diagnosis, and symptom identification. These factors contribute to a growing interest from the users regarding health-related information.

We developed this study with the purpose of promoting the health of spinal cord injury (SCI) patients. SCI patients need to continuously seek health-related information throughout their lives. Health professionals are responsible for providing information at the right time and place, and adjusting it to the patient's needs.

Studies have reported difficulties to health-related educational interventions: the insufficiency or lack of written instructions (Hoffmann, McKenna, Herd, \& Wearing, 2007; Hoffman \& Cochrane, 2009); the vast amount of information necessary for maintaining quality of life (Matter et al., 2009); the different perceptions on information needs between patients/ families and health professionals (Suhonen, Nenonen, Laukka, \& Välimäki, 2005), the lack of follow-up after clinical discharge (Hoffman et al., 2007); the difficulty in understanding written instructions (Hoffman et al., 2007; Hoffman \& Cochrane, 2009); the insufficient communication or lack of coordination between the health team and the patients/family (Hoffman et al., 2007; Hoffman \& Cochrane, 2009); the shortened length of hospital stay (Matter et al., 2009).

The objectives of this study were: to identify the information needs of SCI patients, and produce and validate the contents of self-care training videos for SCI patients.

\section{Background}

Video is an information and communication technology that can be distributed through the television (or DVDs) or through the internet. Over the past decades, video has been used as an educational support in schools, universities, and for the general public through television. Health education and risk prevention using videos has proved to be effective
(Cho \& Chambers, 2014; Dyson, Beatty, \& Matthews, 2010; Shah \& Velez, 2014; Zaffagnini, Russo, Muccioli, $\&$ Marcacci, 2013).

Physical rehabilitation following SCI is based on the training of strategies to compensate for a self-care deficit or irreversible motor impairment, which are the key focus of intervention for the rehabilitation nurse specialist.

Patients learn new behavioral strategies to perform therapeutic or daily living activities, such as relearning how to roll in bed, transfer to the wheelchair and from the wheelchair to another surface/seat, or transferring from the ground to the wheelchair (Matter et al., 2009). Each motor skill implies strengthening the muscles above the spinal cord injury level and requires lever movements, use of push-up methods, inertia, and replacing the use of muscle groups to move a partially paralyzed body (Wheelchair Research Team, 2013). SCI patients do not recover their pre-injury ability to roll in bed, get dressed, hold a glass or get in and out of a vehicle. However, they develop a new set of strategies and motions to perform the self-care activities; otherwise, they become dependent on the help of others.

The use of videos allows simulating the patients' real-life situations that require the use of assistive devices in similar contexts. The production of the videos covers the care aspect by bringing the communication recipient closer to the conveyed message, from the intelligibility of the language used to the type of scenario and comfort created, as well as the familiarity with the type of clothing and environments selected. Videos allow for the simultaneous or sequential inclusion of information through images, sounds, colors, movements, spatial relations, environments or scenarios, as well as the interaction between people or with assistive devices or technologies.

Interactive media are changing the nature of health care provision, and the implications of this change may represent both an opportunity for professionals to expand their way of communicating and a greater responsibility in terms of care effectiveness, quality and safety. Videos are better accepted by patients with low literacy levels, which is an advantage when compared to written materials (Cho \& Chambers, 2014; Shah \& Velez, 2014).

Rehabilitation training is a progressive and dynamic process. The exercises are selected by the multidisciplinary team of professionals and by the 
patient according to their remaining motor skills and the skills acquired during the training (balance, manual dexterity, and strength, among other criteria). Some of these mobility training exercises are highly valued by SCI patients (Simpson, Eng, Hsieh, \& Wolfe, 2012), and the following activities are essential to self-care: trunk balance training (in bed or wheelchair), bed mobility training (bridge exercise, side roll, supine hip rotation, sitting, raising and lowering the lower limbs, among others), orthostatic training (Multidisciplinary Association of Spinal Cord Injury Professionals [MASCIP], 2013) between bars, in standing frame, in front of the bed; joint movement exercises with assistance (passive and/or active assistive exercise) or without assistance (self-mobilization); dressing training; toilet and bathing (shower or bathtub) training; training of transfer between same-height surfaces (for example, wheelchair/bed) or different-height surfaces (wheelchair/couch or car seat).

Some cases require the implementation of respiratory training (Restreppo, Wettstein, Wittnebel, \& Tracy, 2011) with various possible exercises, including incentive spirometry. It is also possible to start the training on bladder emptying through self-catheterization for bladder control in individuals with loss of sphincter function (Cardoso, Queirós, \& Margato, 2006), as well as a bowel management program (MASCIP, 2012).

\section{Research questions}

What are the specific information needs of SCI patients?

What are the contents of the self-care training videos for SCI patients?

\section{Methodology}

This study integrates the qualitative paradigm of understanding the phenomenon under study and the actual relationship between theory and practice. The instrument was designed in two key moments:

1. Preliminary survey study on the information needs of SCI patients (semi-structured interviews).

2. Study on the design/production and validation of a set of videos on rehabilitation and self-care.

The preliminary study to identify the information needs and preferences of presentation (study 1) consisted in interviewing 120 participants during a 4-month period (60 SCI patients hospitalized in a rehabilitation unit and 60 health professionals specialized in rehabilitation: physiatrists, specialist nurses, physical and occupational therapists). In the semi-structured interviews, the direct contact with the participants in their daily lives and care context (rehabilitation unit) was essential. By adopting this measure, we were able to understand the complexity of the rehabilitation process of SCI patients exactly where it takes place, minimizing bias arising from the space-time distancing from that environment.

This interview included eight questions to identify the information needs of SCI patients, of which six were open-ended questions and two were closed-ended questions, placed intentionally in this order so that the closed-ended questions would not influence the open-ended questions (which required a more comprehensive and flexible description of the participants' individual experience). The combination of both types of question (open-ended and closed-ended), was intentional so as to obtain additional information. The content analysis of the results of this interview followed Bardin's theoretical and technical assumptions (2004).

A set of 12 pre-test interviews was conducted (to six health professionals and six SCI patients) to ensure that the terminology used in the questions was intelligible and neutral, thus minimizing the bias caused by poor semantic interpretation or vocabulary influence. The pilot interviews were not included in the same analysis of the set of 120 interviews from the preliminary study.

As for the study on the design and production of the modelling videos (study 2), besides considering the results of the preliminary study, we consulted both the national nursing intervention protocols for SCI patients (Veiga et al., 2011; Cardoso et al., 2006; Henriques et al., 2007) and the international guidelines (Wheelchair Research Team, 2013; MASCIP, 2013; MASCIP, 2012; Restreppo et al., 2011). For the production of the videos, SCI patients were filmed during self-care activities following the safety practices and standards of the institution. With the purpose of maximizing the reach of the videos as models of an inclusive and multicultural society, which was our concern from the start, these models differed in terms of age, gender or culture/nationality. We shot the videos during 8 months, with the collaboration of 
a film technician and a media technician. The audio/ narration was performed by the staff of the institution where the study took place. These collaborators, similarly to the health professionals, were bound by the rules of confidentiality and ethics involved in the work with hospitalized patients/service users, and of protection of the participants' privacy and intimacy. Ten videos were produced (first version) on self-care rehabilitation techniques: elevating the trunk in wheelchair or push-up; incentive spirometry; bladder emptying through self-catheterization in men; bladder emptying through self-catheterization in women; orthostatism in tilt table or standing-frame; standard positioning in bed; transferring to bed with electric lift; transferring a paraplegic patient to a car seat; transferring a quadriplegic patient to a car seat; navigate sidewalks using a wheelchair.

Table 1 summarizes the technical resources and materials necessary for shooting the rehabilitation techniques under study.

Table 1

Resources and materials necessary for shooting the modelling videos under study

\begin{tabular}{|c|c|}
\hline Technique/activity & Necessary materials/resources and space \\
\hline Tilt table or standing frame & $\begin{array}{l}2 \text { Nurses } \\
\text { Wheelchair } \\
\text { Standing frame or tilt table } \\
\text { Safety straps } \\
\text { Available/vacant indoor space }\end{array}$ \\
\hline Transfer from wheelchair to car seat & $\begin{array}{l}\text { Car/vehicle with wheelchair access entry height } \\
\text { Pressure relief cushion } \\
\text { Wheelchair } \\
\text { Transfer board } \\
\text { Outdoor space without traffic }\end{array}$ \\
\hline Transfer with electric lift & $\begin{array}{l}2 \text { Nurses } \\
\text { Wheelchair } \\
\text { Bed } \\
\text { Power plug } \\
\text { Electric lift and canvas or fiber sling/transfer } \\
\text { Vacant ward }\end{array}$ \\
\hline Incentive spirometry & $\begin{array}{l}\text { Bed or Wheelchair } \\
\text { Incentive spirometer } \\
\text { Support table }\end{array}$ \\
\hline Navigating sidewalks using a wheelchair & $\begin{array}{l}\text { Wheelchair with anti-tipping wheels } \\
\text { Sidewalk with room to maneuver and without traffic nearby }\end{array}$ \\
\hline Bladder emptying & $\begin{array}{l}2 \text { Nurses } \\
\text { Wheelchair or bed } \\
\text { Vacant ward, with privacy } \\
\text { Urinal or emesis basin } \\
\text { Lubricated catheters, size } 12 \text { or } 14 \\
\text { Alcohol-based solution for hand hygiene } \\
\text { Washbasin } \\
\text { Sterile gauze pads } \\
\text { Garbage bag }\end{array}$ \\
\hline Bed positioning & $\begin{array}{l}\text { Adjustable bed with safety rails } \\
4 \text { Large pillows } \\
4 \text { Small cushions } \\
\text { Vacant ward }\end{array}$ \\
\hline
\end{tabular}

The contents of the first version of the videos were assessed in an individual unstructured interview to seven experts with recognized professional and curricular experience in rehabilitation. After a brief description of the ongoing study, the videos were sequentially displayed in a computer, with each expert being able to interrupt to comment on/suggest changes for each video, as well as to play again each video or video extracts to better assess the contents. Each expert was asked to critically analyze the safety aspects in each technique, as well as to give suggestions for improving the quality and rigor of the 
information. The experts' suggestions and comments were recorded.

Each interview was digitally transcribed. The experts' suggestions and comments were classified according to their frequency, meaning, legitimacy and relevance for achieving the original purpose of the modelling videos. Bardin's content analysis technique (2004) was then applied to the collected data.

We tried to understand the meanings, ideas, and messages in the experts' interviews by dividing the data into subcategories or dimensions of analysis. The experts' assessment resulted in a list of priority changes to improve the videos.

In order to minimize bias, the contents of the videos were validated by experts from different professional backgrounds (practitioners, academics and scientific/ professional authorities) and regions (Lisbon, Porto and Coimbra). The content validation would be less accurate if we only considered the assessment by two or three experts, which is why we chose a broader and more diversified panel.

A new version of the videos was then prepared during a 3-month period with the introduction of extracts from new footage, additional computer graphics, and new narrative excerpts in the initial prototype. The contents of the second version of the videos were then reassessed by one of the experts who had been appointed by the Portuguese Society of Physical Medicine and Rehabilitation (SPMFR) and was clinical director of the inpatient unit where the study took place. This second intentional assessment was a necessary step for using the videos in a subsequent and more comprehensive study on the impact of the instrument in a sample of SCI patients.

The modelling videos on rehabilitation techniques were produced in a Rehabilitation Medicine Center of the Greater Lisbon area. Formal written authorization was granted by the Board of Directors of the center. The researcher assured that the existing criteria and protocols of the rehabilitation center for teaching self-care techniques would be respected and safeguarded. The filmed individuals were asked to give their consent, after being explained the purpose of the videos (who would have access to the videos, and the possibility of being made available online), the right to refuse or withdraw from the study at any stage of the process, and that there would be no consequences or interference in the health care received by the participants in the rehabilitation center where the study took place. This information was provided in person and the participants signed an informed consent before the footage.

In compliance with the principle of non-maleficence, a panel of experts was asked to validate the technical-scientific content of the videos. Thus, we requested the collaboration of the Portuguese Nurses' Association (Ordem dos Enfermeiros - OE), represented by the Specialty College in Rehabilitation Nursing, and SPMFR, with each entity appointing a consultant for this purpose. In addition to a specialist nurse in rehabilitation appointed by the $\mathrm{OE}$ and a physiatrist from a rehabilitation center appointed by the SPMFR, the panel of experts included two specialist nurses in rehabilitation with more than 20 years of professional practice in a rehabilitation center, and three Professors of Rehabilitation Nursing from Higher Education Nursing Schools (Porto and Coimbra).

\section{Results and Discussion}

A preliminary study analyzed the six open-ended questions according to the dimensions of analysis (thematic analysis) in the answers, i.e. the answers were divided into record units, categorized into dimensions of analysis, and then the frequencies (quantitative analysis) were estimated in the sample. Since the groups of participants had not been compared, the binomial test (mentioned/not mentioned) was applied to the answers. The statistical study of binominal probabilities between both groups of participants (patients and professionals) was used to check for significant differences between the answers of each group and thus to understand the value assigned to information. The Mann-Whitney test was used to compare the scores assigned to the two closed-ended questions.

Similarly to other research studies, the data collected from the sample of 120 participants about the information needs of SCI patients allow concluding that inpatients assign more relative importance to: services that continue the care team/patient relationship after discharge (Breen \& Matusitz, 2010), information on treatments and consultations, and clarification of doubts (Edwards, Krassioukov, \& Fehlings, 2002), and on clinical trials/new technologies. In turn, the interviewed professionals 
gave priority to: the patients' responsibility in self-managing their health (Edwards et al., 2002; Harrison \& Kouzel, 2009), the information on self-care, and the prevention of risks and worsening of the clinical situation.

The differences found between the groups of participants may be a barrier to an efficient communication between professionals and patients. Authors such as Hoffmann and Cochrane (2009) report in their studies the need to adapt the communication and coordination of information among the care team members to the patients' information needs. Suhonen et al. (2005) also concluded that patients prefer receiving information about the disease and treatment, while undervaluing information about the daily management of the disease process, such as self-care after discharge or their rights as patients.

During the validation of the video contents, more than one expert provided suggestions or comments, with similar references from four or five experts on the same aspects, as well as aspects in which all the experts agreed, showing a high level of agreement among the experts. Since the full transcription of the interviews and the more common suggestions in the experts' interviews would become too exhaustive (in a total of one hundred and forty-three suggestions/ references, $n_{\text {total }}=143$ ), we described the most common subcategories in general terms, indicating their absolute frequency value $(n=\mathrm{X})$ : Position or movement of the SCI patient during the techniques/ exercises $(n=26)$; Alternatives to using assistive devices during the techniques $(n=25)$; Changes in shooting image, rhythm, duration or angle $(n=28)$.

The position or movement of SCI patients while performing activities of daily living should optimize their mobility, safety and comfort, as well as ensure the principle of non-maleficence, which is essential to health interventions. The alternatives suggested to the use of assistive devices, which are not always essential for the performance of the techniques, reflect the value assigned by health professionals to assistive equipment/devices. The inclusion in the videos of all the suggested assistive devices, as well as their quality, when these are not strictly necessary for the SCI patient's safety and autonomy is debatable in a context of scarce material resources.

As regards to changes to shooting image, rhythm, duration or angle, these reflect the value assigned to how the message is conveyed, and how this format can influence the content of the message and its ability to promote motor abilities. The video production and editing technologies should, according to the experts, put into evidence the most important details concerning the patients' safety during the performance of techniques or exercises. The experts confirmed that different factors, such as the duration of the exercise, the number of scenes repeated or zooming in on some details can contribute to a better understanding of the message. The shooting angles, when carefully chosen, allow for the visualization of every movement, assistive device or positioning of materials and people. In some cases, it may be necessary to film the same activity or technique under different angles.

The panel of experts suggested that foreign words $(n=8)$, such as push-up, transfer, standing-frame, should be removed from the videos, although, in rehabilitation institutions, the exercises and therapeutic activities are commonly known by their original name, as used by the health professionals who teach them. The terminology mesa de verticalização (tilt table) or standing-frame, sometimes used by health professionals, may also be considered a form of professional jargon, whereas mesa de posição de pé (standing table) could be a more intelligible term. In an attempt to find a compromise between intelligibility for the public and institutional recognition in the final version of the video, we chose to use mesa de verticalização (tilt table). By changing the technical term whereby a therapeutic activity is known in its institutional context, there is the risk of it not being recognized by the message recipients. The suggestions on the prevention of injuries, accidents or falls and on the promotion of an effective performance by the caregiver/SCI patient $(n=16)$ were also highly relevant. Some of these suggestions focused on the importance of using brakes, anti-tipping wheels, immobilizing the lower limbs of SCI patients during transfers, and protecting the their joints or bony prominences during bed positioning and transfers when there are obstacles to body motion.

The experts also suggested adding other messages to the narration, alerting patients to the need for supervision by specialized professionals $(n=4)$ in case of injury during the technique or when performing techniques that pose a higher risk for falls or trauma. 
The prevention of infection $(n=7)$ and pressure ulcers $(n=6)$, the implementation of measures related to comfort, aesthetics or well-being $(n=8)$, the need to emphasize the therapeutic benefits of the technique $(n=3)$ or the promotion of the independence of SCI patients were less often suggested. However, these suggestions were incorporated into the final version of the videos due to their qualitative relevance.

This study focused on the design and production of a video instrument for health promotion/ prevention among SCI patients. At the time of this study, there were no records of similar studies in Portugal, although there were, in other countries, videos in English in areas such as the management of diabetes mellitus, youth tobacco prevention, the use of inhalation therapies, cancer screening tests (for breast, skin or colorectal cancer), or post-surgery rehabilitation, among others (Cho \& Chambers, 2014; Dyson et al., 2010; Shah \& Velez, 2014; Zaffagnini et al., 2013). These studies corroborate the results found in the interviews to the experts, who mentioned that video materials can improve the effectiveness of knowledge transfer in a way that would not be possible with written materials, while also improving motor dexterity and skills of all those who use them. Some limitations of this study relate to the initial methodological options, which were corrected in due time. While designing the survey interviews on the information needs, we planned on producing an online instrument (website) for the dissemination of health information/videos to SCI patients. This could bias the answers, especially in terms of the means for disseminating the necessary information to SCI patients. Due to lack of time and resources, the assessment of the impact of such an instrument and population range would be impractical, which is why we opted for designing and producing a video instrument.

Another relevant limitation relates to the researcher's ability to become a neutral element within the interview environment, to the extent that, by making part of the context as a specialized professional, the researcher could influence the answers, both in the preliminary study and in the study on the design of the video instrument. Thus, we decided to minimize the comments/suggestions during the interviews of both studies.

Other significant limitations were the technological difficulties involved in producing the videos, which became a lengthy (2 years) and costly (camera, sound and image technicians, video editing/ infographics, etc.) process that could, therefore, influence the result obtained in the initial prototype.

\section{Conclusion}

In the preliminary study, rehabilitation professionals and SCI patients valued relatively different information. SCI patients revealed more uncertainty, often providing answers such as don't know, unlike the group of health professionals, who had more assertive and substantiated opinions. In general, the groups had different priorities.

The themes/items related to sexual dysfunction, respiratory retraining and mental health were more often addressed by the health professionals than among the group of SCI patients.

Finally, in the study on the design and content validation of the video instrument, the seven experts referred that videos offer more educational benefits than written materials, such as manuals or leaflets. All the experts assessed the first version of the 10 videos as reasonable to very good in promoting motor skills. Some mentioned that the videos were compelling and useful to provide information, and all pointed out the need to produce more videos on additional or longer rehabilitation techniques than those included in the videos. Three experts referred the need to produce more specific videos to different levels of dependence/autonomy, allowing patients to select the best videos for their clinical situation. In general, the display or monitoring of the videos did not result in any negative comments or opinions on the rigor or use of the videos. The experts' suggestions indicated that some information should be explicitly provided by the narrator; otherwise, they will be overlooked by the patient.

The final version of the modelling videos, after the incorporation of the experts' suggestions, has more communicational and technical-scientific rigor than the original prototype. The content validation performed by the experts was a decisive step to ensure the effectiveness and safety of the audiovisual instrument under study.

Some movements or strategies must be explained through narration and, if omitted, the patient will 
have difficulties retaining the information. The use of infographics (captions, graphics, titles) in video editing was valued and often recommended by the panel of experts.

It is worth mentioning that, in the event of a lack of material resources or time for the production of modelling videos on self-care techniques or therapeutic activities, we recommend the use of less modelling techniques, favoring rigor and quality in the design and production of the videos.

\section{References}

Bardin, L. (2004). Análise de conteúdo (3a ed.). Lisboa, Portugal: Edições 70.

Breen, G. M., \& Matusitz, J. (2010). An evolutionary examination of telemedicine: A health and computer-mediated communication perspective. Social Work in Public Health, 25(1), 59-71. doi: 10.1080/19371910902911206

Cardoso, F. M., Queirós, P. J., \& Margato, C. A. (2006). Técnicas de reabilitação I ( $4^{\mathrm{a}} \mathrm{ed}$.). Coimbra, Portugal: Formasau.

Cho, N., \& Chambers, R. (2014). The potential of video in patient education post skin biopsies University of Ottawa Journal of Medicine, 4(2), 32-35. doi: http://dx.doi.org/10.18192/ uojm.v4i2.1161

Dyson, P. A., Beatty, S., \& Matthews, D. R. (2010). An assessment of lifestyle video education for people newly diagnosed with type 2 diabetes. Journal of Human Nutrition and Dietetics, 23(4), 353-359. doi: 10.1111/j.1365-277X.2010.01077.x

Edwards, L., Krassioukov, A., \& Fehlings, M. G. (2002). Importance of access to research information among individuals with spinal cord injury: Results of an evidencedbased questionnaire. Spinal Cord, 40(10), 529-535. doi:10.1038/sj.sc.3101364

Harrison, K. L, \& Kouzel, O. (2009). Cyberchondria: Is online health information good for patients? British Medical Journal, 17(b4813). Retrieved from http://www.medscape. $\mathrm{com} /$ viewarticle $/ 714410$ ? $\mathrm{src}=\mathrm{rss}$

Henriques, F. M., Cruz, A. G., Afonso, J. A., Ferreira, M. B., Costa, M. C., \& Coimbra, M. M. (2007). Técnicas de reabilitação II ( $2^{\text {a }}$ ed.). Coimbra, Portugal: Formasau.

Hoffmann, T., McKenna, K., Herd, C., \& Wearing, S. (2007). Written education materials for stroke patients and their carers: Perspectives and practices of health professionals. Topics in Stroke Rebabilitation, 14(1), 88-97. doi: 10.1310/ tsr1401-88

Hoffmann, T., \& Cochrane, T. (2009). What education do stroke patients receive in Australian hospitals? Patient Education and Counseling, 77(2), 187-191. doi: 10.1016/j. pec.2009.03.009
Matter, B., Feinberg, M., Schomer, K., Harniss, M., Brown,P., \& Johnson, K. (2009). Information needs of people with spinal cord injuries. The Journal of Spinal Cord Medicine, 32(5), 545-554. Retrieved from e http://www.ncbi.nlm.nih.gov/ pmc/articles/PMC2792460/

Multidisciplinary Association of Spinal Cord Injury Professionals. (2013). Clinical guideline for standing following spinal cord injury. Retrieved from http://www.mascip.co.uk/wpcontent/uploads/2015/05/Clinical-Guidelines-for-StandingAdults-Following-Spinal-Cord-Injury.pdf

Multidisciplinary Association of Spinal Cord Injury Professionals. (2012). Guidelines for management of neurogenic bowel dysfunction in individuals with central neurological conditions. Retrieved from http://www.mascip.co.uk/ wp-content/uploads/2015/02/CV653N-NeurogenicGuidelines-Sept-2012.pdf

Restreppo, R. D., Wettstein, R., Wittnebel, L., \& Tracy, M. (2011). AARC clinical practice guideline: Incentive spirometry: 2011. Respiratory Care, 56(10), 1600-1604. http://www.rcjournal. com/cpgs/pdf/10.11.1600.pdf

Simpson, L. A., Eng, J. J., Hsieh, J. T., \& Wolfe, D. L. (2012). The health and life priorities of individuals with spinal cord injury: A systematic review. Journal of Neurotrauma, 29(8), 15481555. doi: 10.1089/neu.2011.2226

Shah, R., \& Velez, L. (2014). Effectiveness of software-based patient education on inhaler technique: A clinical study. European Respiratory Journal, 44(sup.58). Retrieved from http://use-inhalers.com/effectiveness-software-basedpatient-education-inhaler-technique-clinical-study?lang=en

Suhonen, R., Nenonen, H., Laukka, A., \& Välimäki, M. (2005). Patients' informational needs and information received do not correspond in hospital. Journal of Clinical Nursing, 14(10), 1167-1176.

Veiga, B., Henriques, E., Barata, F., Santos, F., Santos, I. S., Martins, M. M., ... Silva, P. C. (2011). Manual de normas de enfermagem: Procedimentos técnicos ( $2^{\mathrm{a}}$ ed.). Lisboa, Portugal: Administração Central do Sistema de Saúde. Retrieved from e http://www.acss.min-saude.pt/Portals/0/ MANUAL\%20ENFERMAGEM\%2015_07_2011.pdf

Wheelchair Research Team. (2013). Wheelchair skills training program version 4.2: Manual. Retrieved from http:// www.wheelchairskillsprogram.ca/eng/documents/WSTP_ Manual_4.2.2_approved.pdf

Zaffagnini, S., Russo, R. L., Muccioli, G. M. M., \& Marcacci, M. A. (2013).The videoInsight ${ }^{\circledR}$ method: Improving rehabilitation following anterior cruciate ligament reconstruction: A preliminary study. Knee Surgery, Sports Traumatology, Arthroscopy, 21(4), 851-858. doi: 10.1007/ s00167-013-2392-4 

